\section{Self-harm in older people with depression}

\author{
Comparison of social factors, life events and symptoms
}

\author{
MICHAEL DENNIS, PENNY WAKEFIELD, CAROLINE MOLLOY, \\ HARRY ANDREWS and TREVOR FRIEDMAN
}

\begin{abstract}
Summary Studying non-fatal selfharm in older adults may provide insight into suicidal behaviour in this age group. The objectives of the study were to determine clinical factors that might help to differentiate those older adults with depression who are most at risk of selfharm and suicide. We examined social factors, life events, hopelessness and other depression symptoms in a group of 48 older people with depression referred following an episode of self-harm compared with 50 similarly aged people with depression who had no history of self-harm. The groups were similar in many respects, although those in the selfharm group were more likely to have a poorly integrated social network and were more hopeless.
\end{abstract}

\section{Declaration of interest None. \\ Funding detailed in Acknowledgements.}

The study of self-harm in the elderly may provide a valuable insight into suicide. Episodes frequently involve a high degree of suicidal intent (Pierce, 1987; Merrill \& Owens, 1990). As with completed suicide, there are high rates of depression in elderly people who self-harm (Pierce, 1987; Merrill $\&$ Owens, 1990), and unfortunately there are high rates of subsequent suicide, in particular in those with persistent depression (Hepple \& Quinton, 1997).

\section{METHOD}

\section{Self-harm group}

Seventy-six adults aged 65 years and over who had self-harmed were prospectively studied. They were identified as referrals to the local specialist self-harm team. Written informed consent was obtained from the participant and the following scales were then administered: the Beck Depression Inventory (BDI; Beck \& Steer, 1993a), the Beck Hopelessness Scale (BHS; Beck \& Steer, 1993b), the Suicide Intent Scale (SIS; Beck et al, 1974) and the 15-item Geriatric Depression Scale (GDS-15; Sheikh \& Yesavage, 1986). The research psychiatrist then interviewed participants in a semi-structured manner; 48 of the 70 participants seen by the psychiatrist were diagnosed as having a depressive episode according to ICD-10 criteria (F31-33; World Health Organization, 1992). Levels of social support were also assessed using an instrument designed specifically for the study, the Social Contact Schedule (SCS; further details available from the author upon request). A social network type (Wenger, 1997) was determined from the information obtained from the clinical history, the SCS and the subsequent Life Events and Difficulties interview. Participants were asked to rate their satisfaction with the level of support they were receiving from the statutory and voluntary agencies, and from family and friends, on a visual analogue scale. At further interview environmental effects for the 6 months prior to the index episode of self-harm were studied by means of the Life Events and Difficulties Schedule (LEDS-2; Bifulco et $a l, 1989$ ). All life events and difficulties reported by the participants in the self-harm group were rated at consensus meetings.

\section{Comparison group}

The comparison group consisted of 50 persons aged 65 years or over referred to their local community mental health team for the elderly with an ICD-10 diagnosis of depressive episode (F31-33). Exclusion criteria for this group were a previous episode of self-harm, inability to speak English or a Mini-Mental State Examination (MMSE; Folstein et al, 1975) score $<24$. The assessment process was similar to that in the self-harm group, but the reference point for life events was 6 months prior to onset of the current depressive episode.

\section{Statistical analysis}

Analyses were performed using the Statistical Package for the Social Sciences, version 10 for Windows. Demographic details, risk factors and categorical data are expressed as percentages within groups, and compared with the Pearson chi-squared test (two-tailed) or Fisher's exact test if appropriate. Interval data (rating instruments) and ordinal data were analysed nonparametrically throughout with the Mann-Whitney $U$-test. The results for statistical tests were regarded as significant at or below the $5 \%$ probability level.

\section{RESULTS}

The median SIS score in the self-harm group was 16 (interquartile range 11-20). Two-thirds $(66 \%)$ of people in this group scored 14 or more, indicating significant suicidal intent, and in 32 cases $(67 \%)$ the researcher felt that the participant had wished to die at the time of their self-harm episode. Table 1 compares the main variables in the two study groups.

A similar proportion of participants had first-episode depression compared with recurrent depression or bipolar affective disorder in both the control group (29 out of 50) and the self-harm group (30 out of 48); Pearson $\chi^{2}=0.2$, d.f. $=1, P=0.65$. There was no significant difference for the majority of questions of the GDS-15 between the groups, except that participants in the self-harm group were much more likely to respond 'yes' to the question 'Do you feel your situation is hopeless?' $\left(\chi^{2}=7.3\right.$, d.f. $\left.=1, P=0.007\right)$ and 'no' to the question 'Do you think it is wonderful to be alive now?' $\left(\chi^{2}=3.8\right.$, d.f. $\left.=1, P=0.05\right)$. On the BDI, participants in the self-harm group were more likely to score higher on thoughts of suicide and self-harm than the control group $\left(\chi^{2}=11.6\right.$, d.f. $\left.=3, P=0.009\right)$ and rate themselves as more sad $\left(\chi^{2}=1.5\right.$, d.f. $=3, P=0.04)$, but were less likely to cry $\left(\chi^{2}=9.2\right.$, d.f. $\left.=3, P=0.03\right)$ than the controls.

\section{DISCUSSION}

This study has important service and clinical implications for older people. First, the high rate of suicidal intent among older people with depression who have selfharmed emphasises the importance of such individuals receiving a skilled and detailed 
assessment of both risk and need. This has been recognised in the recently circulated National Institute for Clinical Excellence (2004) guidelines on the hospital management of self-harm, which recommend that older people treated for self-harm should be seen by mental health professionals who are skilled in the assessment of this group of patients and in recognising depression in later life.

Second, there are important implications for the care of elderly people with depression in both primary and secondary care settings. The importance of asking tedium vitae is given emphasis by the similarities in clinical profiles between the groups. Hopelessness is an important discriminator for those at high risk. Unfortunately, there are some questions in the full Beck Hopelessness Scale that are inappropriate for a very elderly population, and the abbreviated ten-item version of the scale has better face validity for older people.

The comparison between our two groups of people with depression gives emphasis to Durkheim's observations on social integration (Durkheim, 1951; first published 1897). Those in the self-harm group were more likely to have a poorly integrated social network than the controls. directly about thoughts of self-harm and Loneliness, lack of support from services

MICHAEL DENNIS, MD, MRCPsych, PENNY WAKEFIELD, BA, Psychiatry for the Elderly, University of Leicester, Leicester General Hospital; CAROLINE MOLLOY, BA, Mental Health Services for Older People, Leicestershire Partnership NHS Trust; HARRY ANDREWS, DM, MRCPsych, Rehabilitation Services, Leicestershire Partnership NHS Trust; TREVOR FRIEDMAN, MB BS, MRCPsych, Brandon Mental Health Unit, Leicestershire Partnership NHS Trust, Leicester, UK

Correspondence: Dr M. S. Dennis, Senior Lecturer and Honorary Consultant Psychiatrist, Psychiatry for the Elderly, University of Leicester, Leicester General Hospital, Gwendolen Road, Leicester LE5 4PW, UK. Tel: 01162 584597; fax:01162 73III5; e-mail: msd4@le.ac.uk

(First received 12 January 2004, final revision 16 September 2004, accepted 29 September 2004) and poor integration in the community therefore appear to be important factors in determining suicidal behaviour in older adults. Both groups had similar rates of severe independent life events, and the rate of approximately $40 \%$ in each group experiencing severe life events during the 6-month study period is comparable with other UK studies (Murphy, 1982; Lam et al, 1987; Evans \& Katona, 1993). Life events are important therefore in the aetiology of depression and self-harm, but there was no excess of events in the self-harm group compared with the control group. Life events do not act alone as precipitating factors for selfharm in elderly people with depression, although they may act as precipitating factors in particularly predisposed individuals. Their role in interaction with other factors, in particular social support, appears to be influential.
Table I Elderly people with depression: comparison between those who did and did not have an episode of self-harm

\begin{tabular}{|c|c|c|c|c|}
\hline & $\begin{array}{l}\text { Self-harm } \\
\text { group }\end{array}$ & $\begin{array}{l}\text { Control } \\
\text { group }\end{array}$ & $P^{\prime}$ & \\
\hline Age, years: median (IQR) & $77(70-83.75)$ & $76(70.75-81)$ & 0.85 & $(z=-0.2)$ \\
\hline Female, \% & 65 & 60 & 0.6 & $\left(\chi^{2}=0.2\right)$ \\
\hline Living alone, \% & 71 & 59 & 0.2 & $\left(\chi^{2}=1.5\right)$ \\
\hline Poorly integrated social network, \% & 76 & 52 & $0.02 *$ & $\left(\chi^{2}=5.6\right)$ \\
\hline Any independent severe life event, \% & 42 & 41 & 0.9 & $\left(\chi^{2}=0.03\right)$ \\
\hline Any major difficulty, \% & 36 & 27 & 0.4 & $\left(\chi^{2}=0.7\right)$ \\
\hline Perceived community support: median (IQR) & $50(10-90)$ & $80(50-100)$ & $0.025^{*}$ & $(z=-2.2)$ \\
\hline $\begin{array}{l}\text { Perceived support from family and friends: median } \\
\text { (IQR) }\end{array}$ & $80(4 I-100)$ & $90(72-100)$ & 0.20 & $(z=-1.3)$ \\
\hline $\begin{array}{l}\text { Weekly contacts with statutory services, } n \text { : median } \\
\text { (IQR) }\end{array}$ & $0(0-2)$ & $\mathrm{I}(0-3.3)$ & 0.06 & $(z=-1.9)$ \\
\hline $\begin{array}{l}\text { Weekly contacts with family and friends, } n \text { : median } \\
\text { (IQR) }\end{array}$ & $7(3-8)$ & $4(1-7)$ & 0.06 & $(z=-1.9)$ \\
\hline Total weekly contacts, $n$ : median (IQR) & $7.25(5-10)$ & $6(3.4-11)$ & 0.46 & $(z=-0.7)$ \\
\hline GDS-I5 score: median (IQR) & $9(7-11.5)$ & $9(6-10)$ & 0.32 & $(z=-1.0)$ \\
\hline BDI score: median (IQR) & $23(15-33)$ & $20(14-26)$ & 0.1 & $(z=-1.6)$ \\
\hline BHS I0-item score: median (IQR) & $7(3-8.5)$ & $4(2-7)$ & $0.047^{*}$ & $(z=-2.0)$ \\
\hline BHS 20-item score: median (IQR) & $12(6.25-17)$ & $10(6-13)$ & 0.21 & $(z=-1.3)$ \\
\hline
\end{tabular}

BDI, Beck Depression Inventory; BHS, Beck Hopelessness Scale; GDS, Geriatric Depression Scale; IQR, interquartile range.

I. Interval and ordinal data presented as medians (upper and lower quartiles) with Mann-Whitney $U$-test $P$, and categorical data as percentages with Pearson chi-squared test $\left(\chi^{2}\right.$ d.f. $\left.=I\right)$.

$* P<0.05$.

\section{ACKNOWLEDGEMENTS}

We thank the self-harm team and community mental health teams of the Leicestershire Partnership NHS Trust for their help in recruiting patients, Nicky Spiers for statistical advice, and Research into Ageing and Help the Aged for their financial support to the project.

\section{REFERENCES}

Beck, A. \& Steer, R. (1993a) Beck Depression Inventory Manual. San Antonio, TX: Psychological Corporation.

Beck, A. \& Steer, R. (1993b) Beck Hopelessness Scale Manual. San Antonio, TX: Psychological Corporation.

Beck, A., Schuyler, D. \& Herman, J. (1974)

Development of suicidal intent scales. In Prediction of Suicide (eds A. Beck, H. Resnik \& D. Lettieri). Bowie, MD: Charles Press.

Bifulco, A., Brown, G., Edwards, A., et al (1989) Life Events and Difficulties Schedule (LEDS-2). London: Royal Hollowayand Bedford New College,University of London.

Durkheim, E. (195I) Suicide. New York: Free Press.

Evans, S. \& Katona, C. (1993) Epidemiology of depressive symptoms in elderly primary care attenders. Dementia, 4, 327-333.

Folstein, M., Folstein, S. \& McHugh, P. (1975) 'MiniMental State': a practical method for grading the cognitive state of patients for the clinician. Journal of Psychiatric Research, 12, 189-198.

Hepple, J. \& Quinton, C. (1997) One hundred cases of attempted suicide in the elderly. British Journal of Psychiatry, I7I, 42-46.

Lam, D., Brewin, C., Woods, R., et al (1987) Cognition and social adversity in the depressed elderly. Journal of Abnormal Psychology, 96, 23-26.

Merrill, J. \& Owens, J. (1990) Age and attempted suicide. Acta Psychiatrica Scandinavica, 82, 385-388.

Murphy, E. (1982) Social origins of depression in old age. British Journal of Psychiatry, 14I, 135-142.

National Institute for Clinical Excellence (2004) Self-harm. The Short-Term Physical and Psychological Management and Secondary Prevention of Self-Harm in Primary and Secondary Care. London: NICE.

Pierce, D. (1987) Deliberate self-harm in the elderly. International Journal of Geriatric Psychiatry, 2, 105-110.

Sheikh, J. \& Yesavage, J. (1986) Geriatric Depression Scale: recent evidence and development of a shorter version. In Clinical Gerontology: A Guide to Assessment and Intervention (ed. T. L. Brink), pp. 165-173. New York: Haworth.

Wenger, G. C. (1997) Social networks and the prediction of elderly people at risk. Aging and Mental Health, I, 3II-320.

World Health Organization (1992) Internationa Statistical Classification of Diseases and Related Health Problems (ICD-10). Geneva: WHO. 